GA-C21941

\title{
ITER CONVERTIBLE BLANKET EVALUATION
}

\author{
by \\ C.P.C. WONG and E. CHENG*
}

${ }^{*}$ TSI Research Inc.

$$
\begin{array}{r}
\text { SEP } 251855 \\
\text { OSTI }
\end{array}
$$

Prepared Under

Subcontract No. ITER-GA-4002

Raytheon Engineers and Constructors

Ebasco Division 


\section{DISCLAIMER}

Portions of this document may be illegible in electronic image products. Images are produced from the best available original document. 


\section{ABSTRACT}

Proposed International Thermonuclear Experimental Reactor (ITER) convertible blankets were reviewed. Key design difficulties were identified. A new particle filter concept is introduced and key performance parameters estimated. Results show that this particle filter concept can satisfy all of the convertible blanket design requirements except the generic issue of $\mathrm{Be}$ blanket lifetime. If the convertible blanket is an acceptable approach for ITER operation, this particle filter option should be a strong candidate. 


\section{PURPOSE}

The purpose of this study is to review and evaluate proposed scenarios and mechanical concepts for the insertion and/or removal of solid blanket/shield materials, and, if appropriate, to recommend a convertible blanket option for ITER. 


\section{INTRODUCTION}

Three shield/blanket design scenarios have been proposed for ITER. The first scenario is to replace the blanket-shield segment between burn plasma phase (BPP) and extended plasma phase (EPP) phases (the 1994 reference design scenario). Two key concerns of this scenario are the uncertain availability of tritium during the BPP (assuming Canadian is the sole source of tritium supply) and the high cost of the blanket segment replacement.

The second scenario is the in-situ conversion of the shield to breeding blanket. In coordination with the selection of the SS and water-cooled shield design, different convertible options have been proposed by Japan and Europe. A review of these options was completed by I.N. Sviatoslavsky of University of Wisconsin. The key difficulty identified is the reliable transfer of solid breeder during the shield/blanket conversion phase. Different approaches in solving this problem have strong impacts on blanket neutronics, thermal and tritium handling performances.

The third scenario, the ITER Conceptual Design Activity (CDA) scenario, is to start the BPP phase with a breeding blanket. The key concern for this scenario is the high initial $R \& D$ cost and the potentially higher complexity, and therefore lower reliability, of the blanket/machine design, especially with the inclusion of tritium extraction system.

The work reported in this document is to provide an independent review of the proposed convertible blankets and to recommend possible design options. 


\section{GOALS AND REQUIREMENTS OF THE CONVERTIBLE BLANKET}

The convertible blanket design has the following goals and requirements:

1. The blanket must be convertible from a non-breeding shield to a breeding blanket without removing or disturbing the mechanical structure of the shield/blanket constructed for the BPP and EPP operations.

2. Materials that are not replaced for EPP must have a lifetime at least $1 \mathrm{MW} \cdot \mathrm{a} / \mathrm{m}^{2}$ and have a high probability of achieving a lifetime of $3 \mathrm{MW} \cdot \mathrm{a} / \mathrm{m}^{2}$.

3. The goal for tritium breeding is 0.4 to 0.8 during the EPP phase of ITER.

4. The blanket must meet all heat removal and shielding requirements of both BPP and EPP phases.

5. All coolant connections are to be located at the top of the machine.

6. The blanket must meet all reliability and safety requirements.

7. The blanket must be compatible with other components.

Additional preferences are:

8. Minimize cost, maximize use of reduced activation materials, maximize design simplicity, maximize Demo relevance, and minimize the conversion time between BPP and EPP.

9. Minimize the perturbation of the 1994 ITER-EDA shield design, which is shown in Fig. 1.

10. Segment the blanket poloidally into sub-modules whenever possible, in order to match the repair scenario of the 1994 ITER-EDA shield design.

Preference 10 has been added for the purposes of this study. Since the presentation of the convertible blanket options (described in Section 2 above) in the early part of 1994, the design of the reference shield began to take shape. As shown in Fig. 1, the design consists of a hot isostatic pressed (HIPped) box structure including the first wall, side walls, end walls and vertical and horizontal ribs, made from SS and cooled by water. The maintenance approach is to cut sub-segments of the shield module from the poloidal module and remove them remotely from the fusion power core for replacement or repair. The distribution pipes are cut and re-welded remotely, which is a very difficult operation. 
Therefore, for this study, in the process of identifying suitable convertible blanket option for ITER, the goal of conserving the poloidal segmentation approach was added in the evaluation.

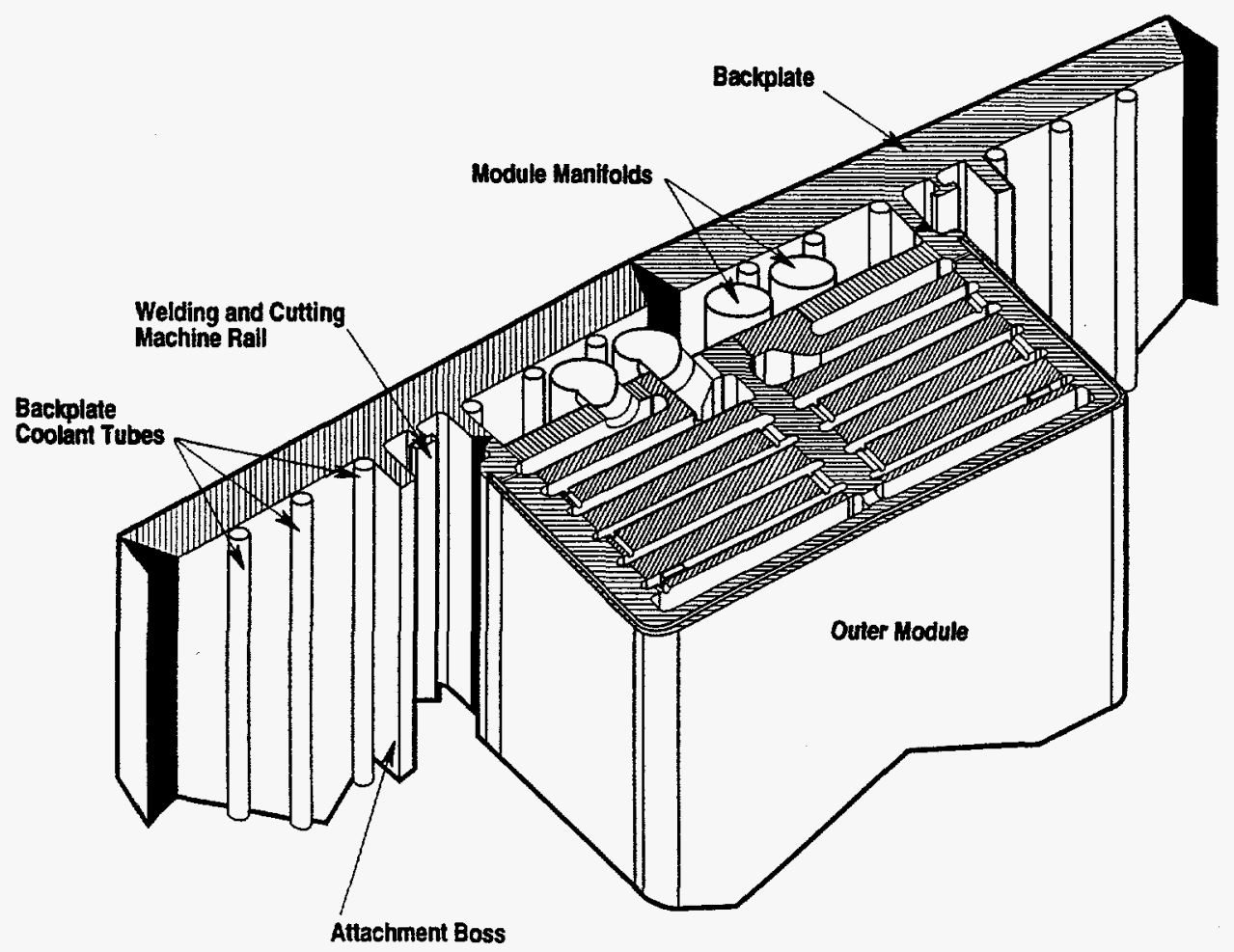

Fig. 1. ITER-EDA 1994 shield design. 


\section{REVIEW OF THE MATERIAL TRANSFER OF DIFFERENT CONVERTIBLE BLANKET OPTIONS}

Several convertible blanket options have been proposed by Japanese and European designers, and they were reviewed by I.N. Sviatoslavsky of University of Wisconsin [1]. The following sections summarize the proposed schemes and chamber configurations, whose purpose is to solve the most difficult problem of filling the chamber with solid breeder in order to convert a shield design to a breeding blanket for the EPP.

\subsection{JAPANESE DESIGNS}

1. Mixed pebble bed design (Fig. 2). The area surrounding the coolant tubes is packed with a $2 \mathrm{~mm}$ Be pebble bed for BPP. The packed bed outside the tubes is later filled with $\mathrm{Li}_{4} \mathrm{SiO}_{4}$ or $\left(\mathrm{Li}_{2} \mathrm{O}\right)$ solid of $0.1 \mathrm{~mm}-0.2 \mathrm{~mm}$ diameter mixed with $\mathrm{Be}$ of the same size as the breeder for EPP.

2. Layered design (Fig. 3). The breeder and multiplier are in separate plate panels. Three breeder panels $(1,2$ and $3 \mathrm{~cm}$ deep) are empty during BPP. These panels are filled with breeder during EPP.

3. Breeder inside tube (BIT) design (Fig. 4). The BIT design consists of concentric tubes with inside tubes holding the breeder and with the multiplier filling out the space between tubes. The breeder tubes could be empty or filled with shielding material during BPP. For the latter case, the shielding material will need to be replaced by breeding material during EPP.

4. Breeder outside tube (BOT) design (Fig. 5). The layered BOT design has multiplier and breeder in separate panels. The breeding material will need to be filled in for the EPP.

5. Flowing ceramic breeder design (Fig. 6). This design has the Be in front and the moving breeder at the back during EPP. A non-breeding moving ceramic can be used during BPP.

\subsection{EUROPEAN DESIGNS}

1. BIT design (Fig. 7). The European BIT design uses $\mathrm{Li}_{2} \mathrm{ZrO}_{3}$ in the inner tubes of concentric tubes during EPP. This design was presented in more detail than the others. This conversion time was said to be 8 months. Experimental 
verification of pebble bed transport behavior under the filling operation was performed. Various particles transfer schemes were considered, including pneumatic, mechanical (e.g. drive screw), and gravity options.

2. BOT mixed bed design (Fig. 8 ). The chamber, with water cooling tubes, is filled with Be pebbles during BPP and a breeder material is added for the EPP.

\subsection{U.S. BALL-DESIGN}

Sviatoslavsky has proposed the $5 \mathrm{~cm}$ stainless steel ball design with large cooling tubes shown in Figs. 9 and 10. During the BPP, the tubes are filled with cooling water and during the EPP, with thin walled SS spheres, $5 \mathrm{~cm}$ in diameter, containing a mixture of $\mathrm{Be}$ and $\mathrm{Li}_{2} \mathrm{O}$ breeder. To extract tritium, the breeder spheres are removed from the blanket in batches. Water can be used to flush the balls in and out. An active mechanical deflector is used to direct the balls to the right channel. This mechanical deflector concept has the best chance of controlling the distribution of the solid breeder. Issues of bridging under normal and off-normal operation (e.g. deflector malfunction and damaged ball) will still need to be addressed.

The major uncertainty of this design is its tritium breeding ratio (TBR) performance. With the selected single-ball-in-tube configuration, and with the mixed neutron multiplier and breeder filling up the inside of the ball, the volume fraction of neutron multiplier will be relatively low. In order to increase the volume fraction of the neutron multiplier, it can be used to fill the space between the tubes, but this may not be adequate. The tritium breeding performance of this concept will need to be demonstrated.

With the relatively large ball and amount of multiplier and breeder mixture, the power generated from the ball can be quite high. Therefore, the issue of heat removal will need to be addressed.

\subsection{COMMON DESIGN APPROACH AND DESIGN DIFFICULTIES}

The five Japanese and two European designs use the common approach of filling the shield with neutron multiplier during the BPP and adding in tritium breeding material during the conversion operation. They have the common difficulty of designing the SS and Be-filled structure to last for the duration of BPP and EPP. The U.S. ball-design fills the water channel with Be-breeder-filled SS spheres during EPP. But in order to get 
adequate TBR, the space between tubes will also need to be filled with Be during BPP. In general, all eight designs require the configuration of continuous $8-10 \mathrm{~m}$ high poloidal channels as breeder material chambers. Because of the tokamak shield/blanket configuration, they all have one or more of the design difficulties of uniform distribution, particle mix and power distribution. Unless solved, these design difficulties will cause problems in the temperature control of different components.

In terms of breeding material distribution and control, the following design difficulties can be stated:

The U.S. ball-design has the best approach for material delivery. The key difficulty is the fitting of the relatively large constant size ball channels and the corresponding ball distribution system into the tokamak configuration. This will have to be demonstrated.

Both Japanese and European BIT designs will have serious difficulties in configuring the particle flow distribution system into the module. This is more difficult when the breeder tubes are of different sizes.

The BOT designs will have more difficulty in particle filling and control than BIT designs because of the long and curved rectangular panels or channels. The difficulty will be compounded by the interference of the necessary radial structural supports with the particle filling and distribution system.

The most difficult design problem for getting a uniform breeder distribution is the filling of the neutron multiplier bed with a mixture of neutron multiplier and breeder. Without a simple concept for vibrating the packed bed, it is difficult to guarantee the needed uniform distribution.

The remaining proposed option is the flowing ceramic breeder. This is an interesting option with a better control of the delivery and distribution of the breeder. It has the disadvantage of a relatively large void space in the low density moving particle chamber, requiring a thicker blanket to achieve the same shielding performance. As pointed out by Sviatoslavsky, there are also the issues of using a moving bed of ceramic in a fusion reactor, mainly material erosion concerns. 

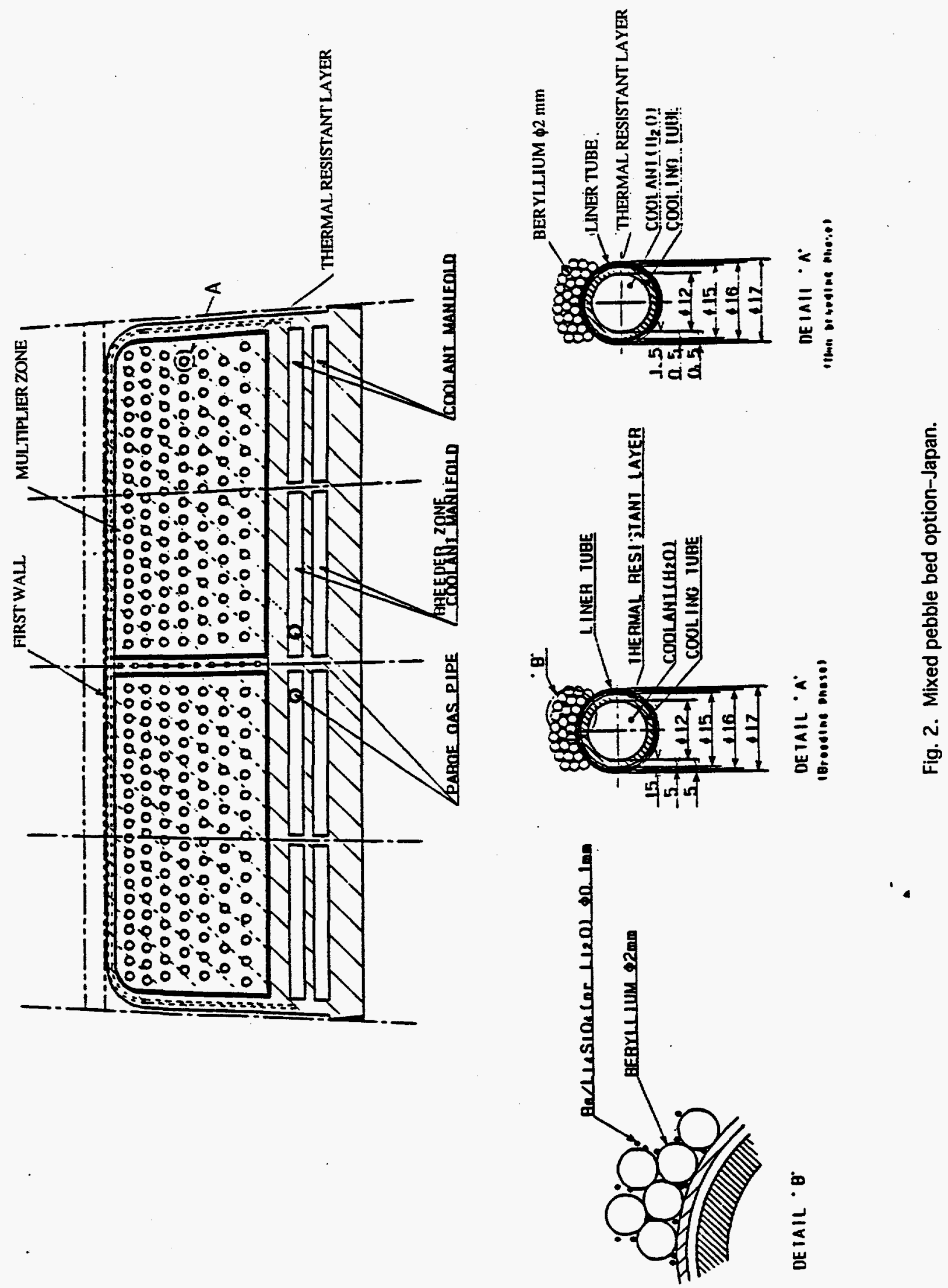

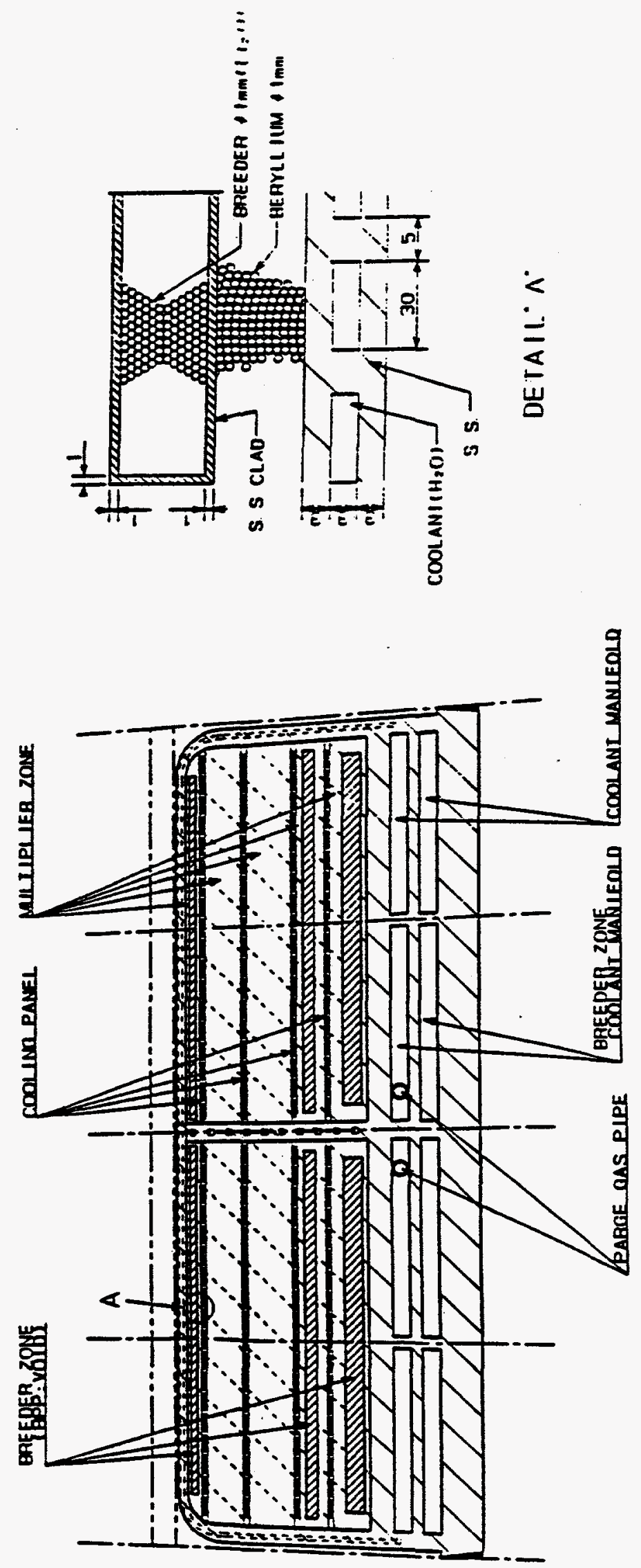

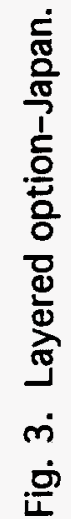



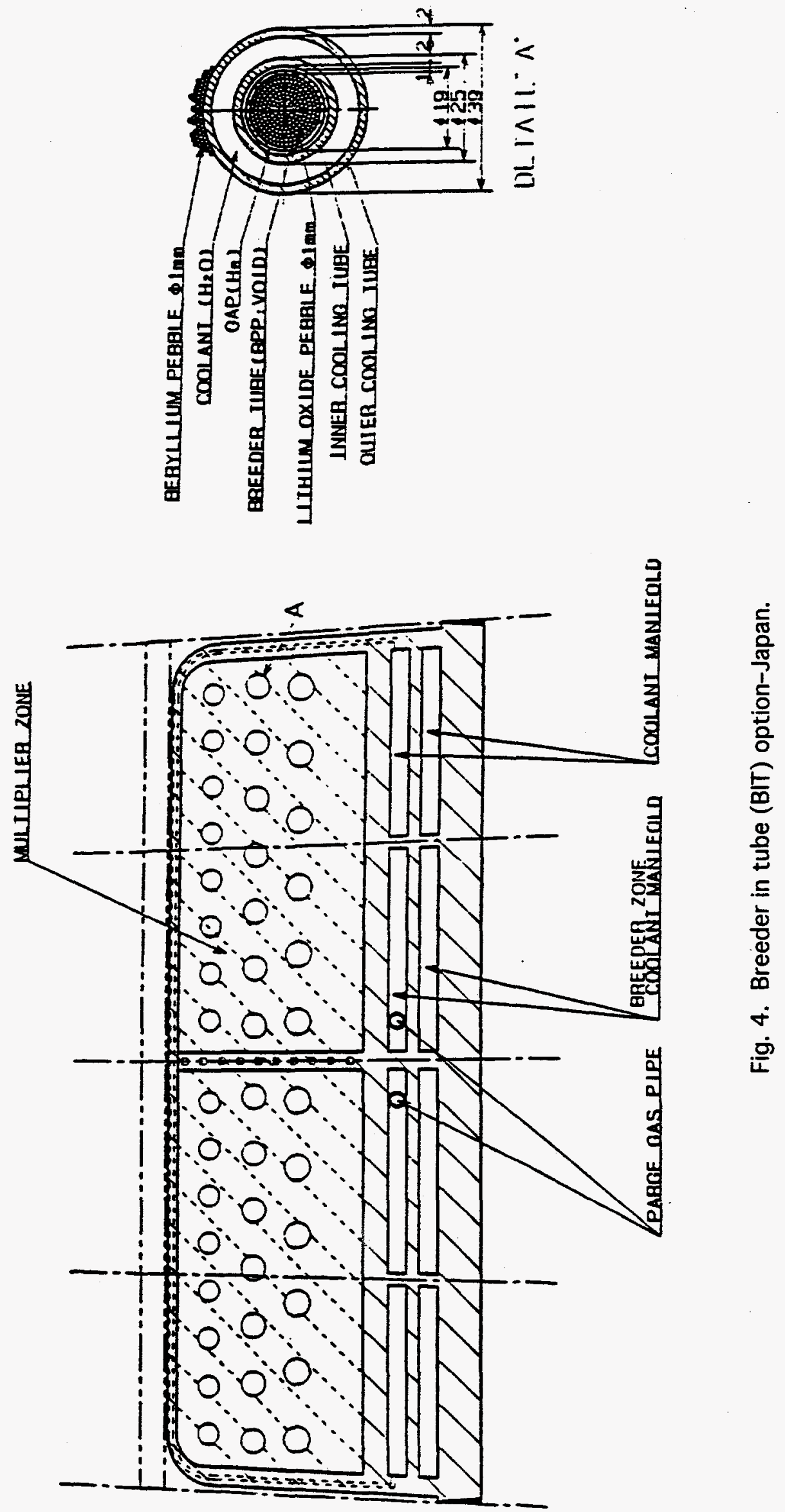

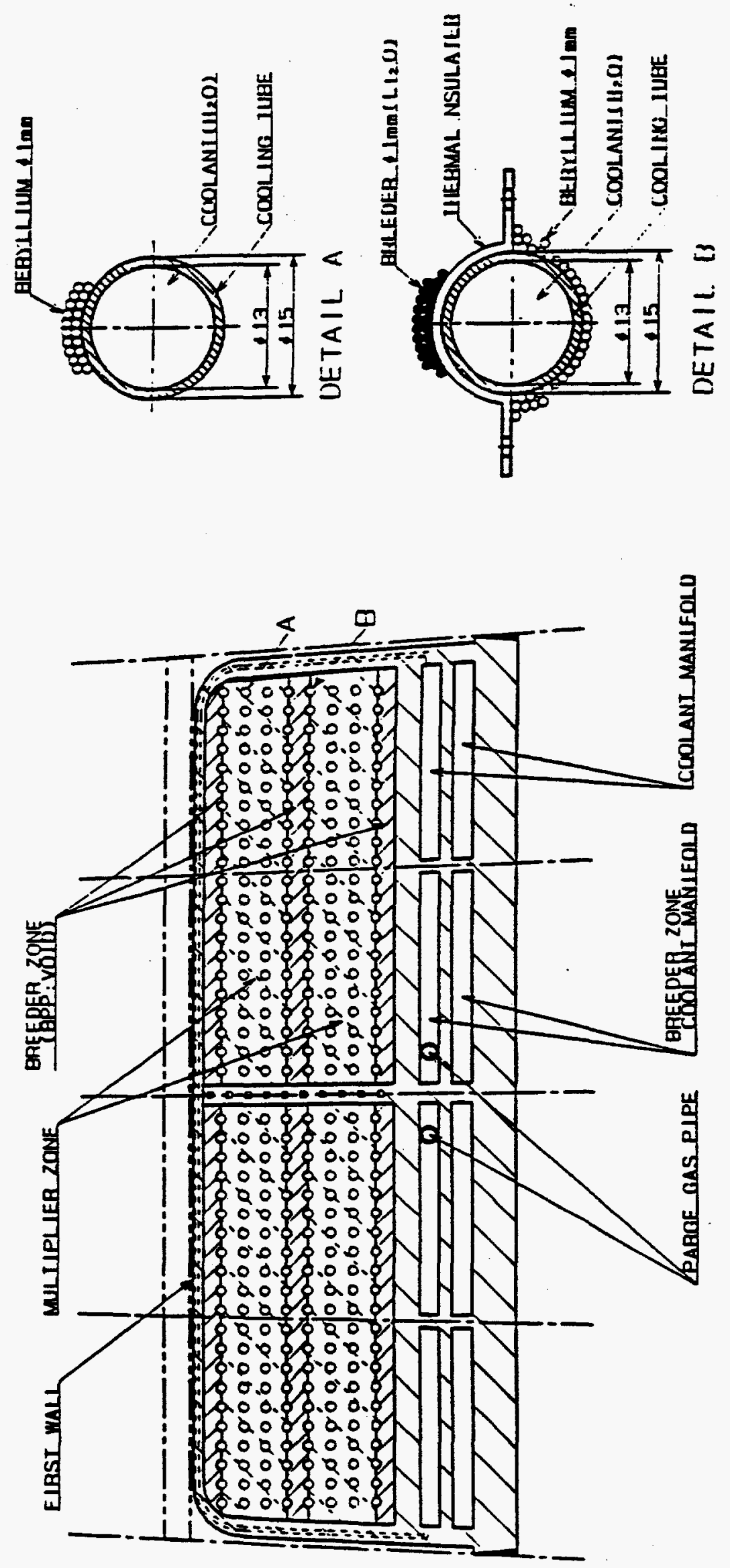

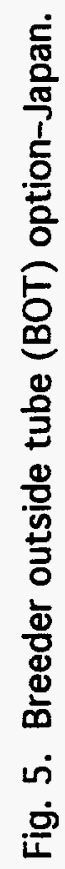




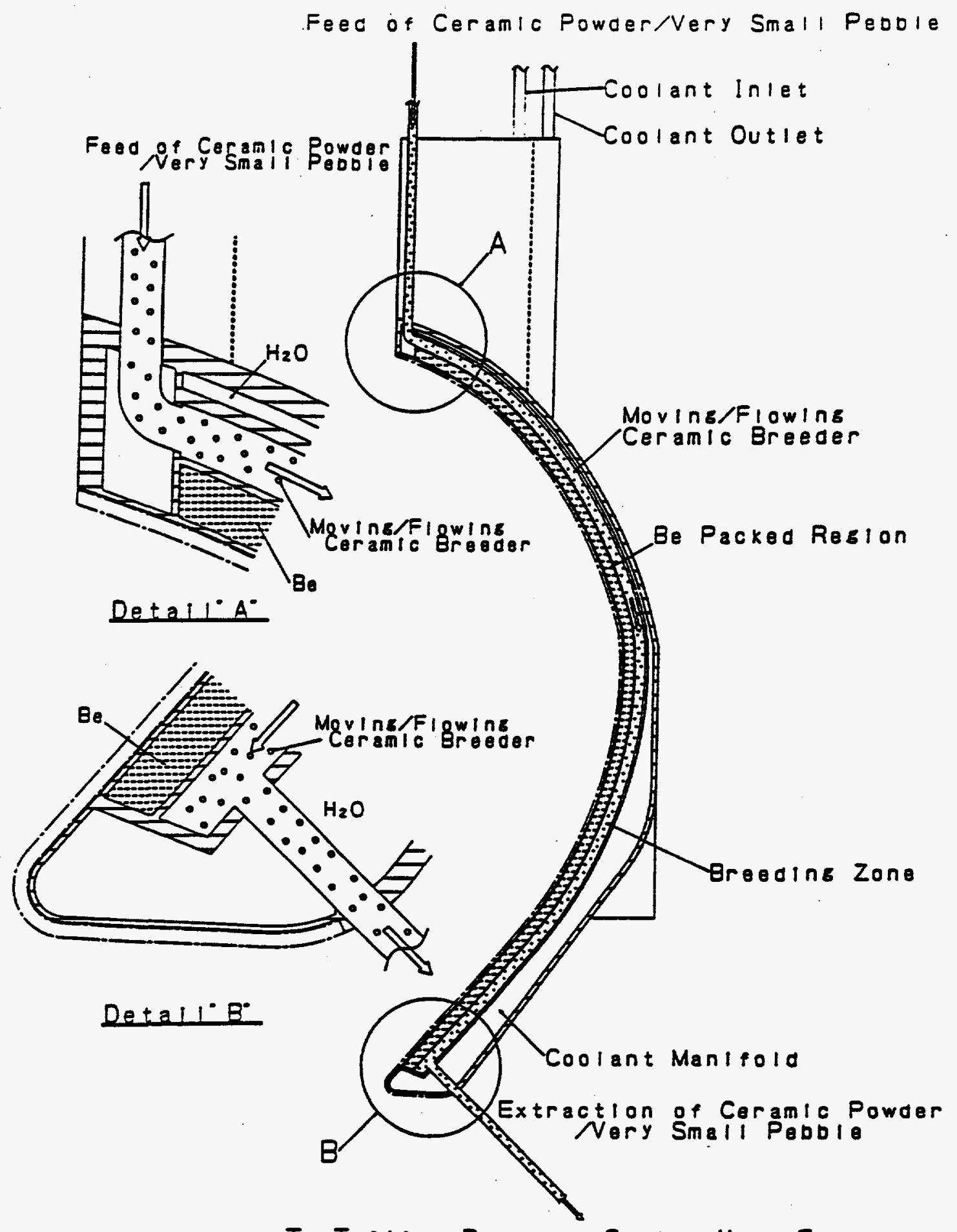

To Tritium Recovery System Heat Exchanger

Fig. 6. Flowing ceramic bed option-Japan. 
EQUATORIAL SECTION

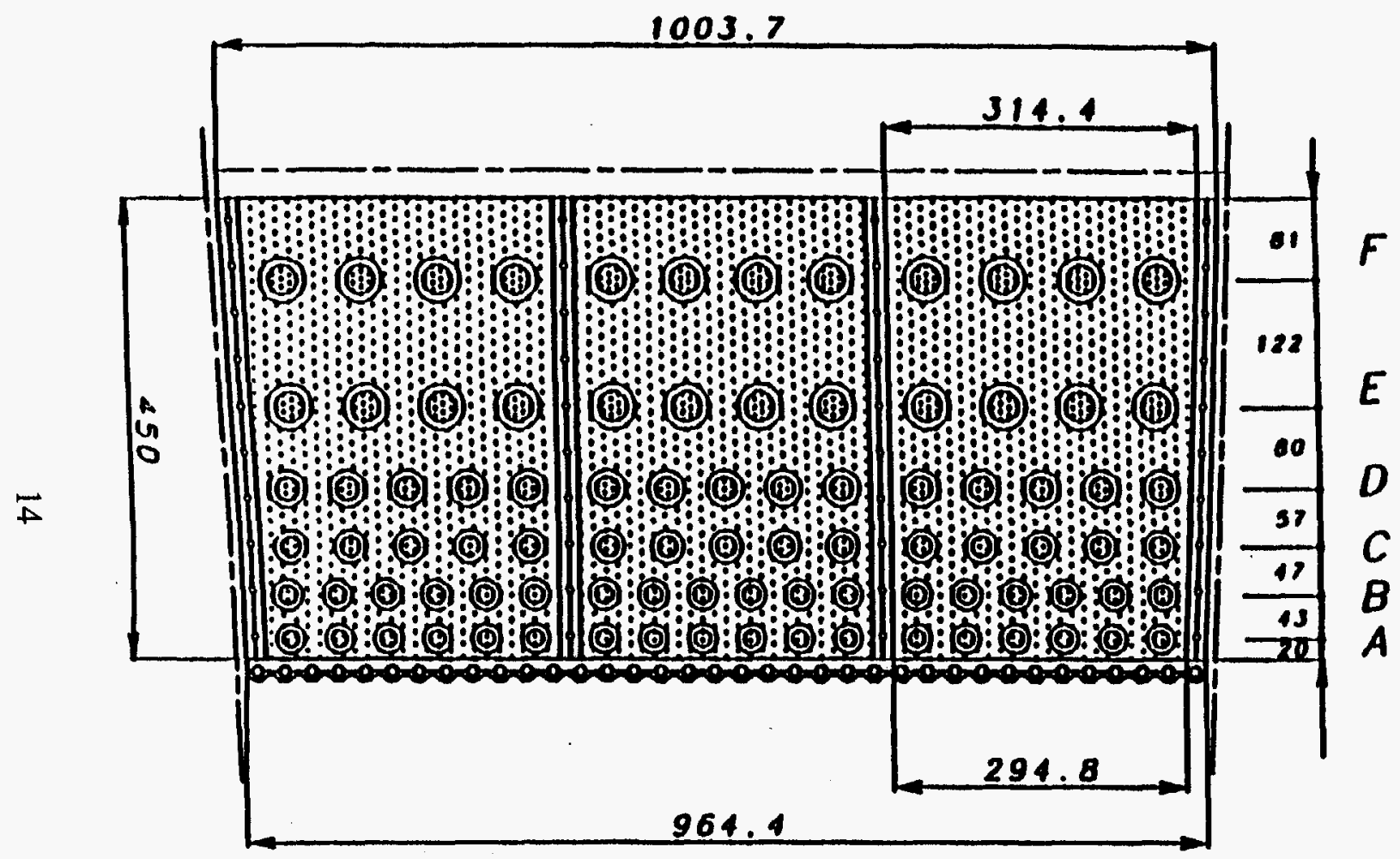

DETAIL OF BREEDING ELEMENT

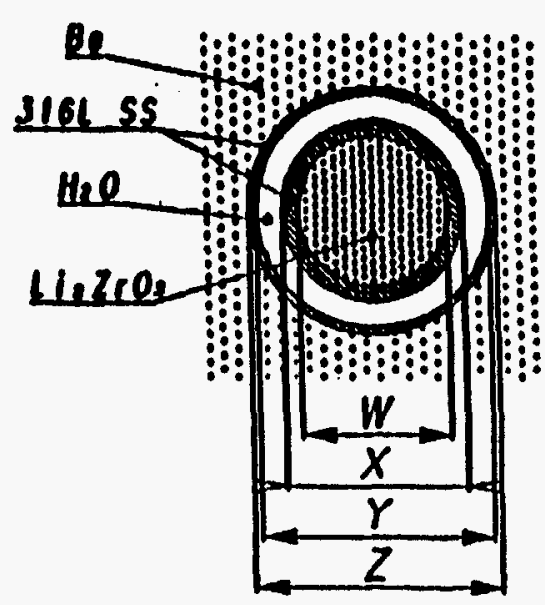

\begin{tabular}{|c|c|c|c|c|c|c|}
\cline { 3 - 7 } \multicolumn{1}{c|}{} & \multicolumn{1}{c|}{$P \mid$} & $X$ & $Y$ & $Z$ & \multicolumn{1}{c|}{$P$ IUA1 } \\
\hline$A$ & 16.2 & 20 & 27.2 & 29 & 49.1 & 39 \\
\hline$B$ & 17.4 & 21.2 & 28.1 & 30.2 & 19.1 & 39 \\
\hline$C$ & 19.2 & 23.1 & 30.6 & 32.6 & 59 & 16.8 \\
\hline$D$ & 22.6 & 27.6 & 31.8 & 37.2 & 59 & 16.8 \\
\hline$E$ & 28.8 & 35 & 12.2 & 15 & 73.7 & 58.5 \\
\hline$F$ & 28.8 & 35 & 12.2 & 15 & 73.7 & 58.5 \\
\hline
\end{tabular}

Fig. 7. Breeder in tube (BIT) option-Europe. 


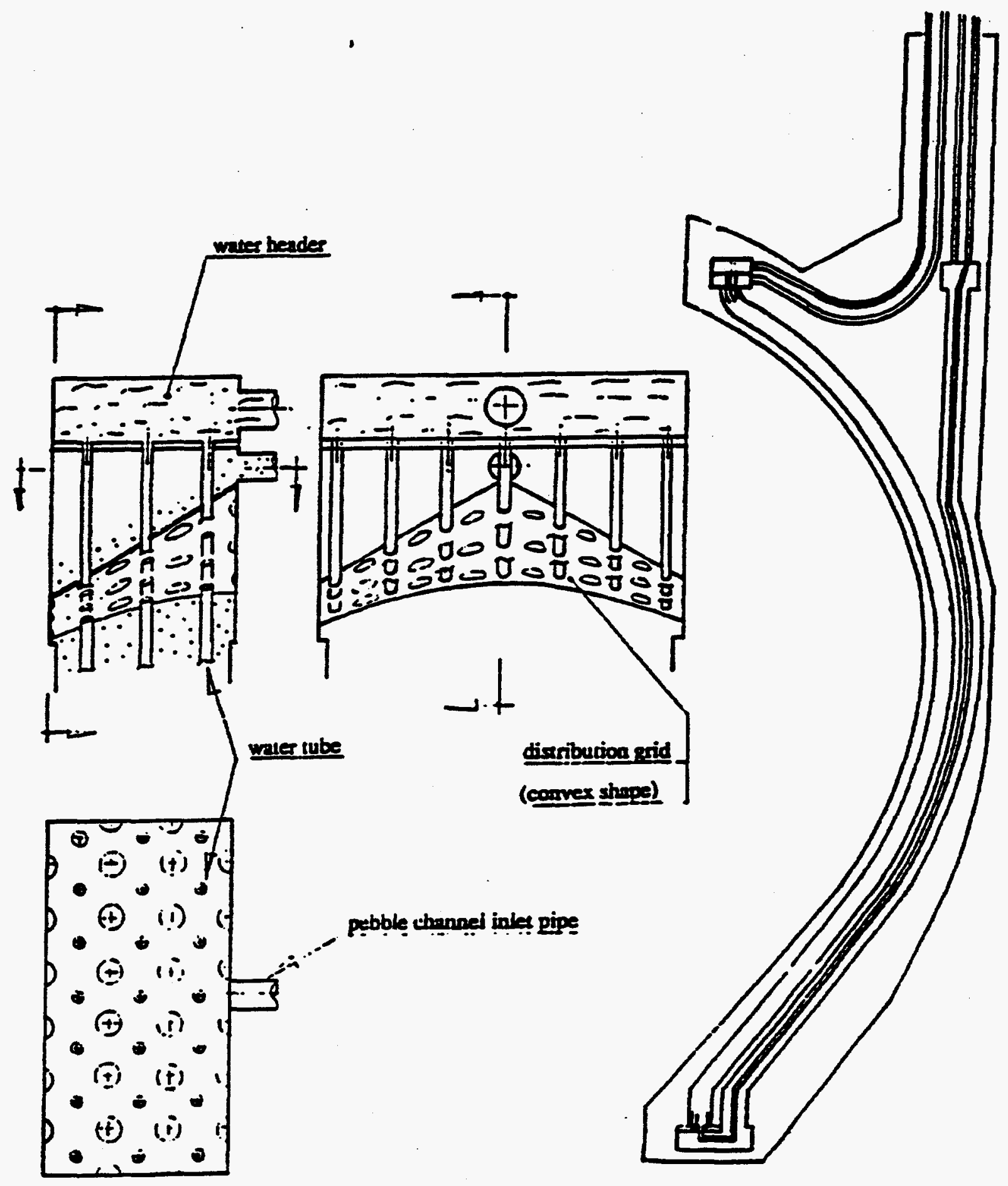

Fig. 8. (a) Mixed pebble bed option-Europe, (b) single pebble channel/mixed bed option-Europe, (c) Sandwiched double pebble channel/mixed bed optionEurope, (d) Concentric pipe filling/mixed pebble bed option-Europe. (Page 1 of 4 ). 


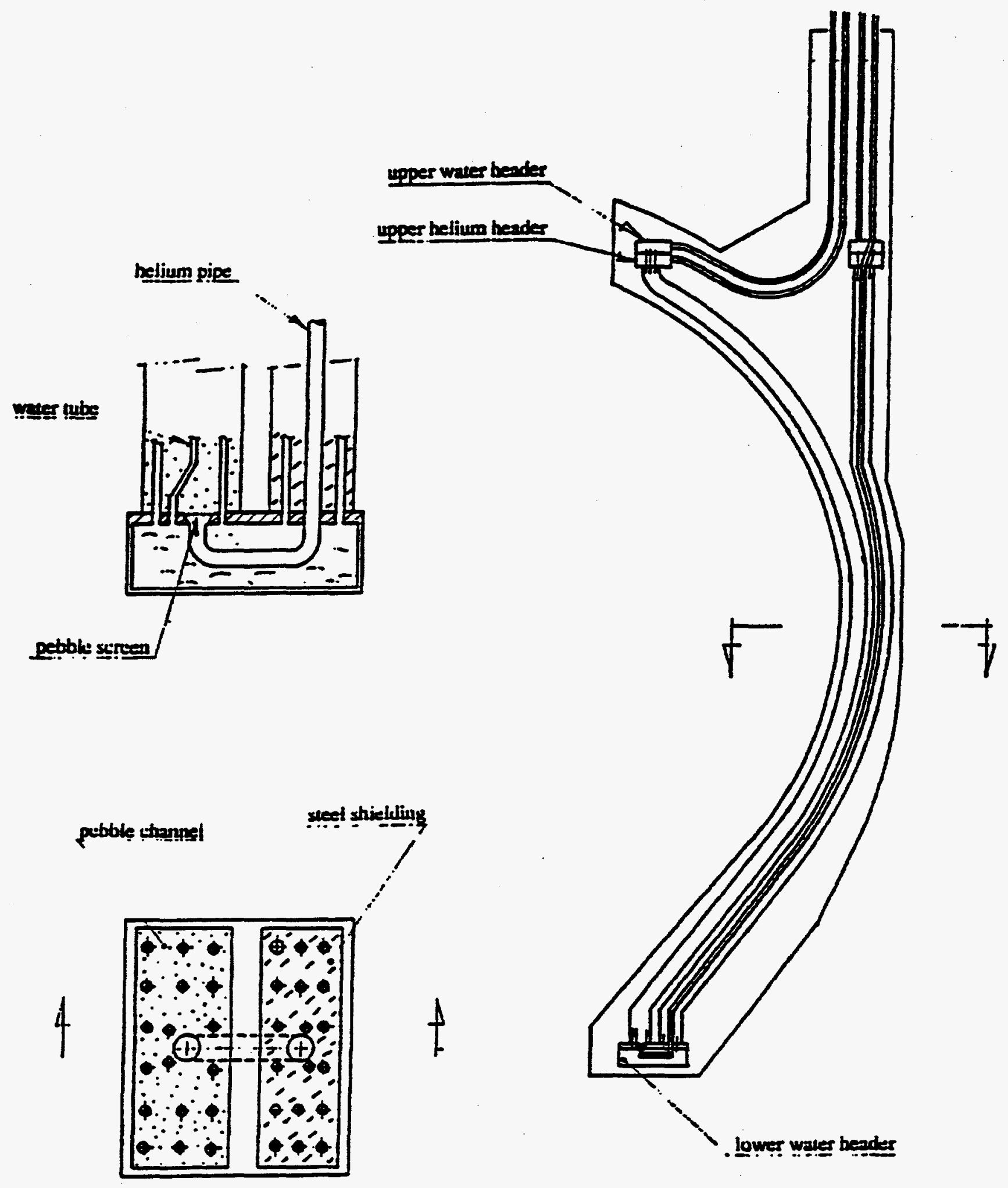

Fig. 8. (a) Mixed pebble bed option-Europe, (b) single pebble channel/mixed bed option-Europe, (c) Sandwiched double pebble channel/mixed bed optionEurope, (d) Concentric pipe filling/mixed pebble bed option-Europe.

(Page 2 of 4 ) 


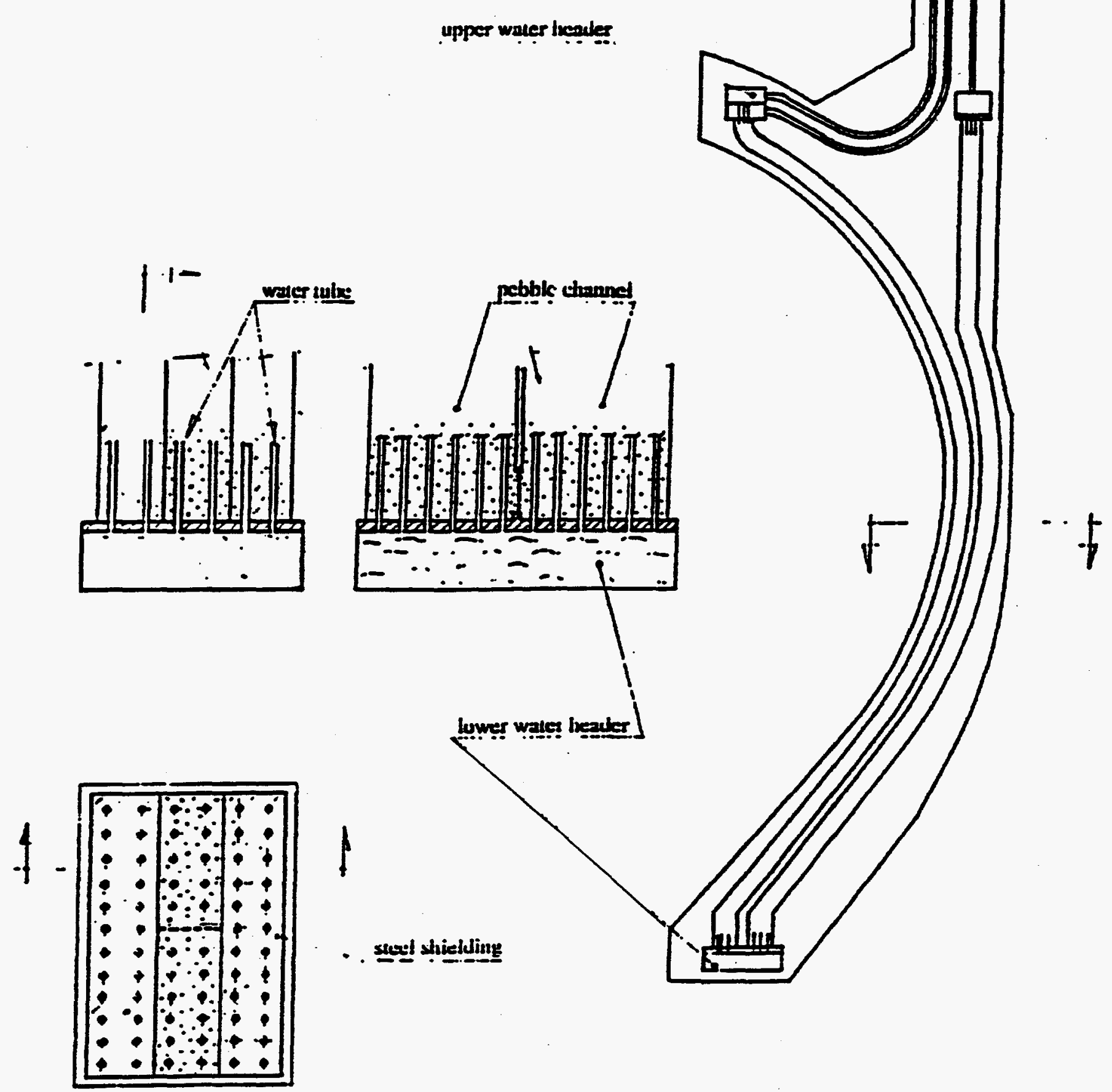

Fig. 8. (a) Mixed pebble bed option-Europe, (b) single pebble channel/mixed bed option-Europe, (c) Sandwiched double pebble channel/mixed bed optionEurope, (d) Concentric pipe filling/mixed pebble bed option-Europe. (Page 3 of 4 ) 


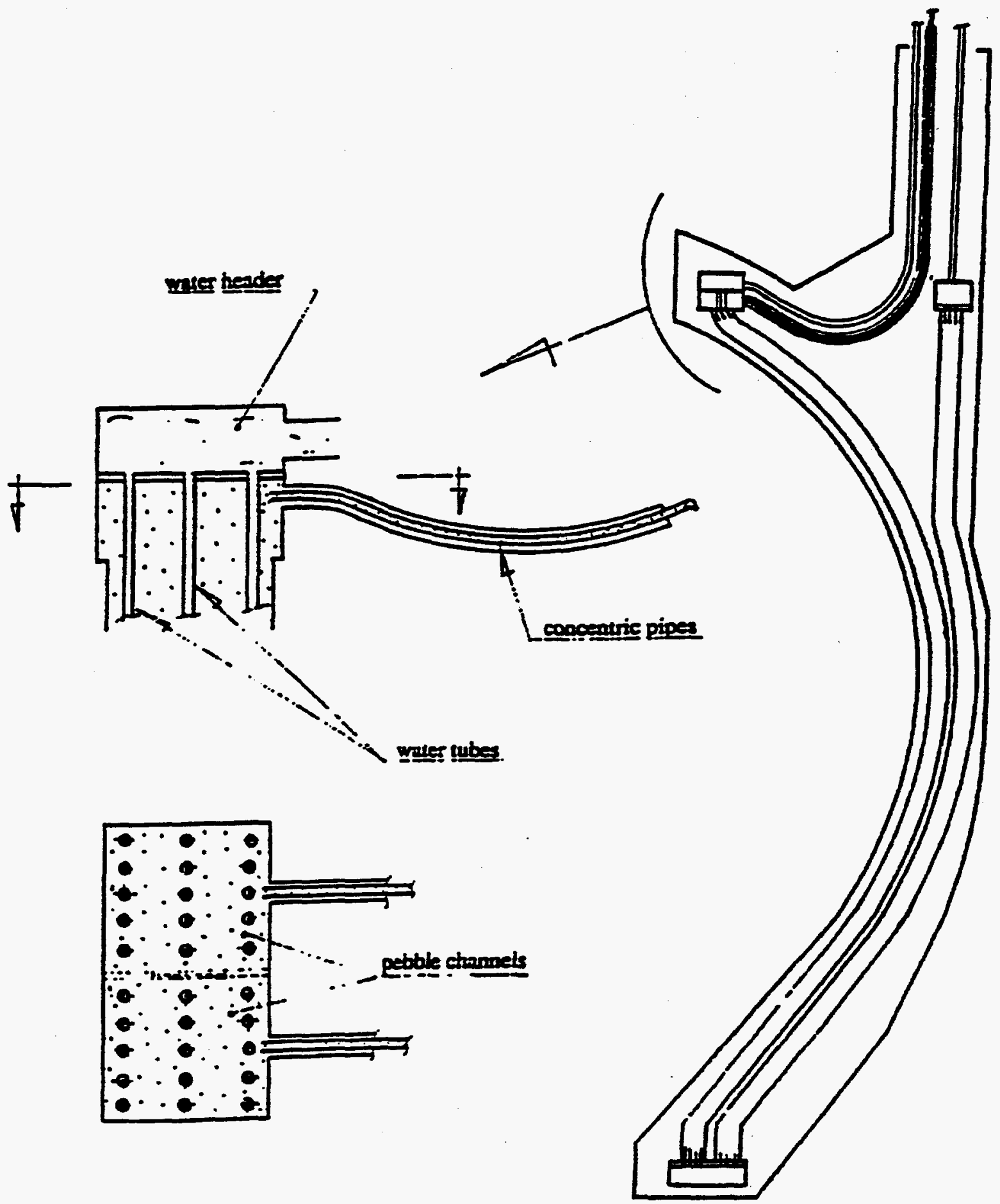

Fig. 8. (a) Mixed pebble bed option-Europe, (b) single pebble channel/mixed bed option-Europe, (c) Sandwiched double pebble channel/mixed bed optionEurope, (d) Concentric pipe filling/mixed pebble bed option-Europe. (Page 4 of 4 ) 


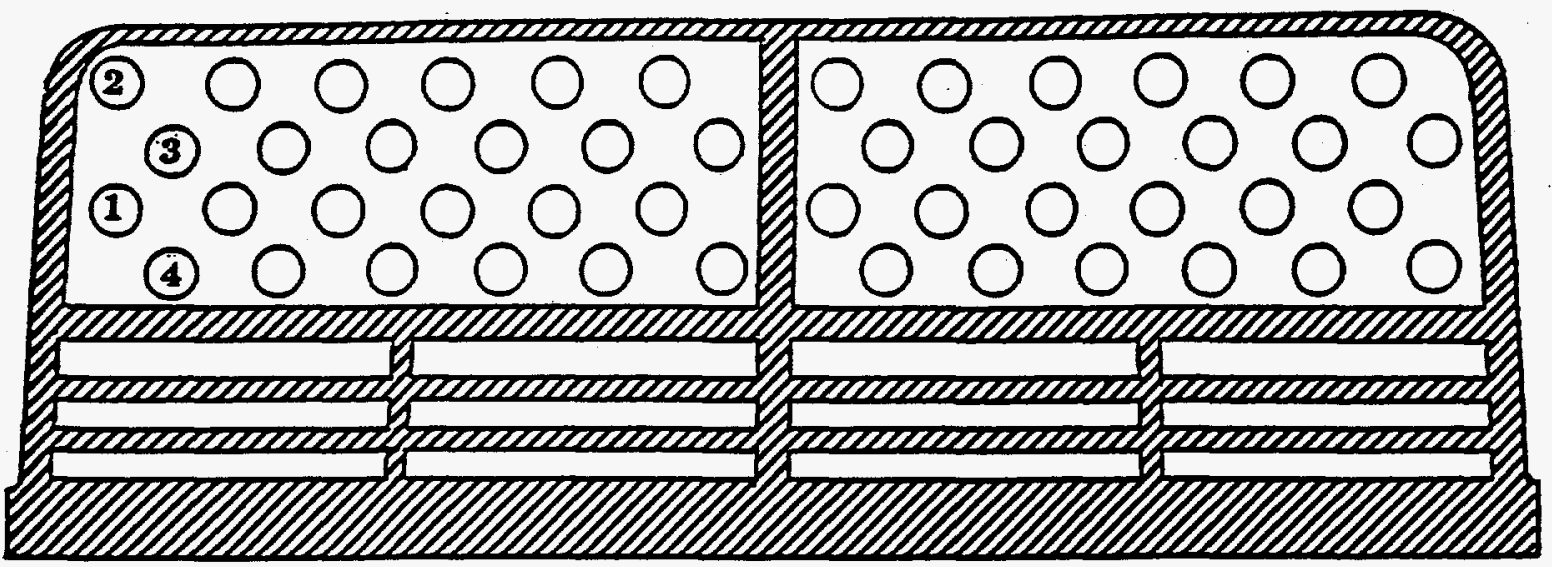

Midplane Cross Section with Numbered Chamels

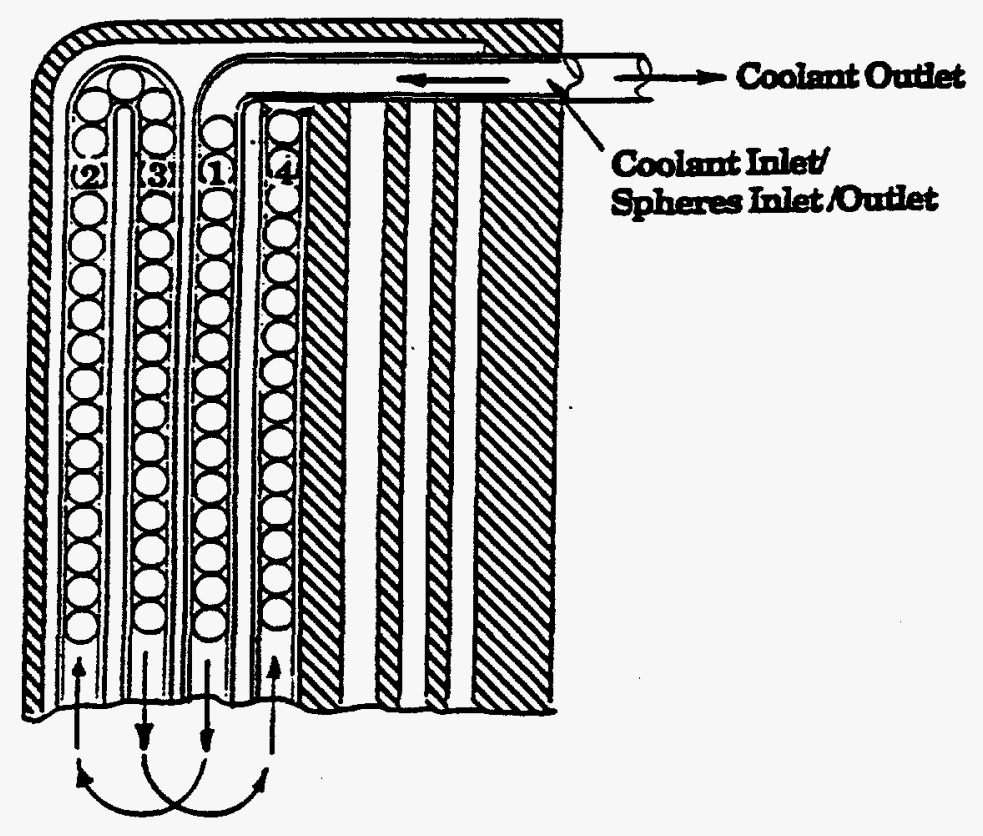

\section{Top Side View with Corresponding Chamel Numbers}

Fig. 9. Midplane cross section and top side view of interchangeable spherical breeder container option. 


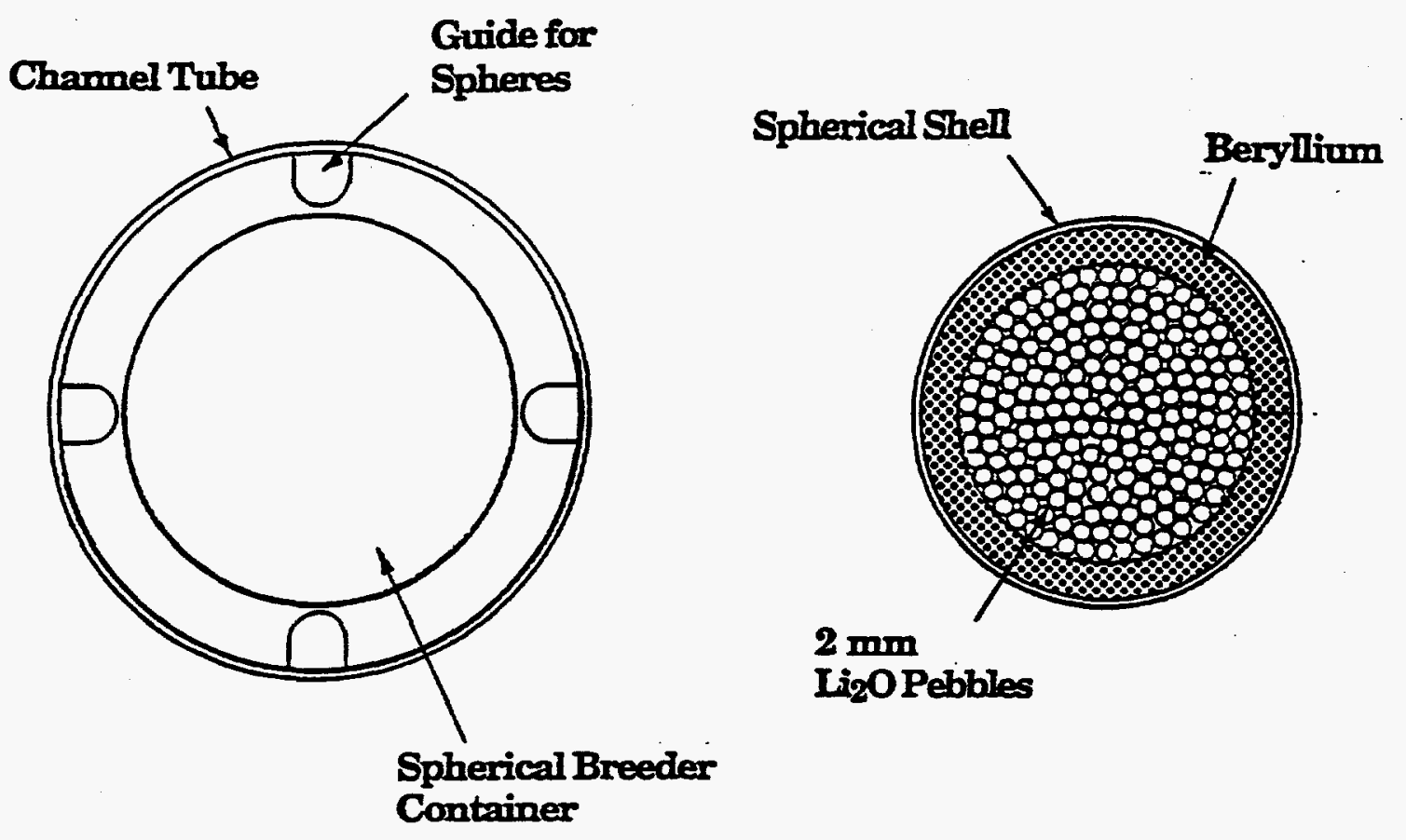

Cross Section of Sphere

Fig. 10. Top view of sphere in tube and cross section of breeder container option. 


\section{FILTER DESIGN OPTION}

We propose a filter design to address many of the design difficulties discussed in Section 4. As shown in Fig. 11, the general configuration of the reference water-cooled shield design can be maintained. The needed modification is the insertion from the bottom of the sub-module tritium purge flow tubes. The inlets, outlets and distribution manifolding of the purge flow tube bundle are located at the bottom of the sub-module. The inlet and outlet pipes of the manifold are at the back of the shield/blanket, similar to the existing water coolant manifolds.

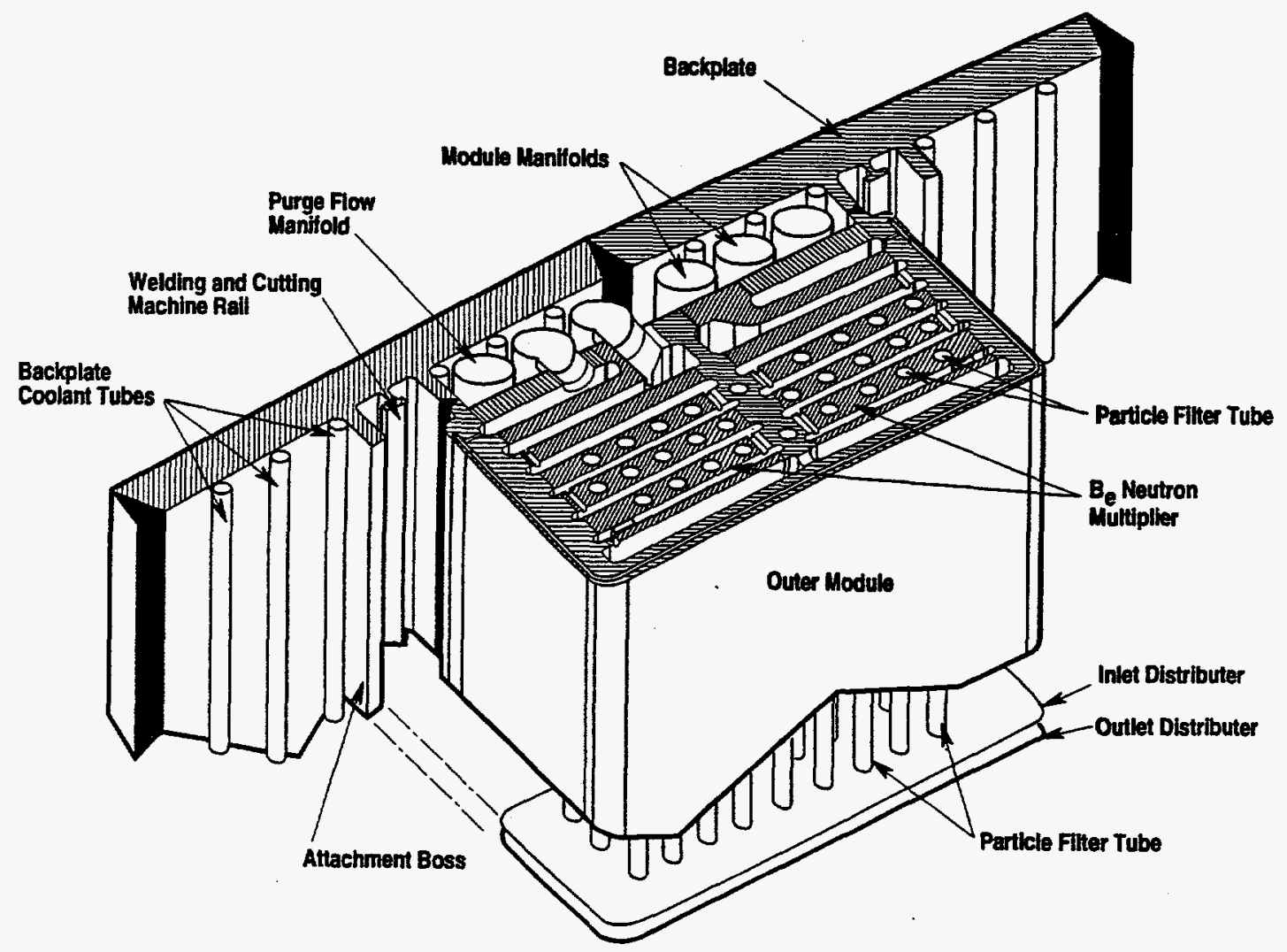

Fig. 11. Blanket module with particle filter tube.

Inside each purge tube, the inlet and outlet flow compartments are separated by a porous filter as shown in Fig. 12. This porous filter can be in the form of a vertical plate, helical strip or cylindrical tube. A cylindrical filter is illustrated as an example. The filter porous material can be metallic or ceramic. An example of the ceramic foam product is 
given in Ref. 2. The flowing medium can be water or helium. For this scoping study, helium is used as an example. During the BPP, the helium coolant or clean water can be circulated in the purge flow tubes. To transition from BPP to EPP, a small amount of solid breeder in the size range of tens to hundreds of microns can be added to the coolant, forming a two phase dilute system. With suitable selection of filter porosity, porous size and particle dimensions, a given amount of solid can be deposited onto the porous filter as the mixture flows through the tube and filter. Operating in the same manner as a swimming pool filter system with the solid breeder serving as to the diatomite filter powder, the solid breeder will continue to deposit onto the filter until all the suitable openings are filled and the filter reaches an equilibrium pressure. Small platelets can be an alternate to small particles. As in swimming pool filters, the flow direction can be reversed and the solid materials can be flushed out and changed. This allows the flexibility of changing breeder material or changing the enrichment of the lithium breeder.

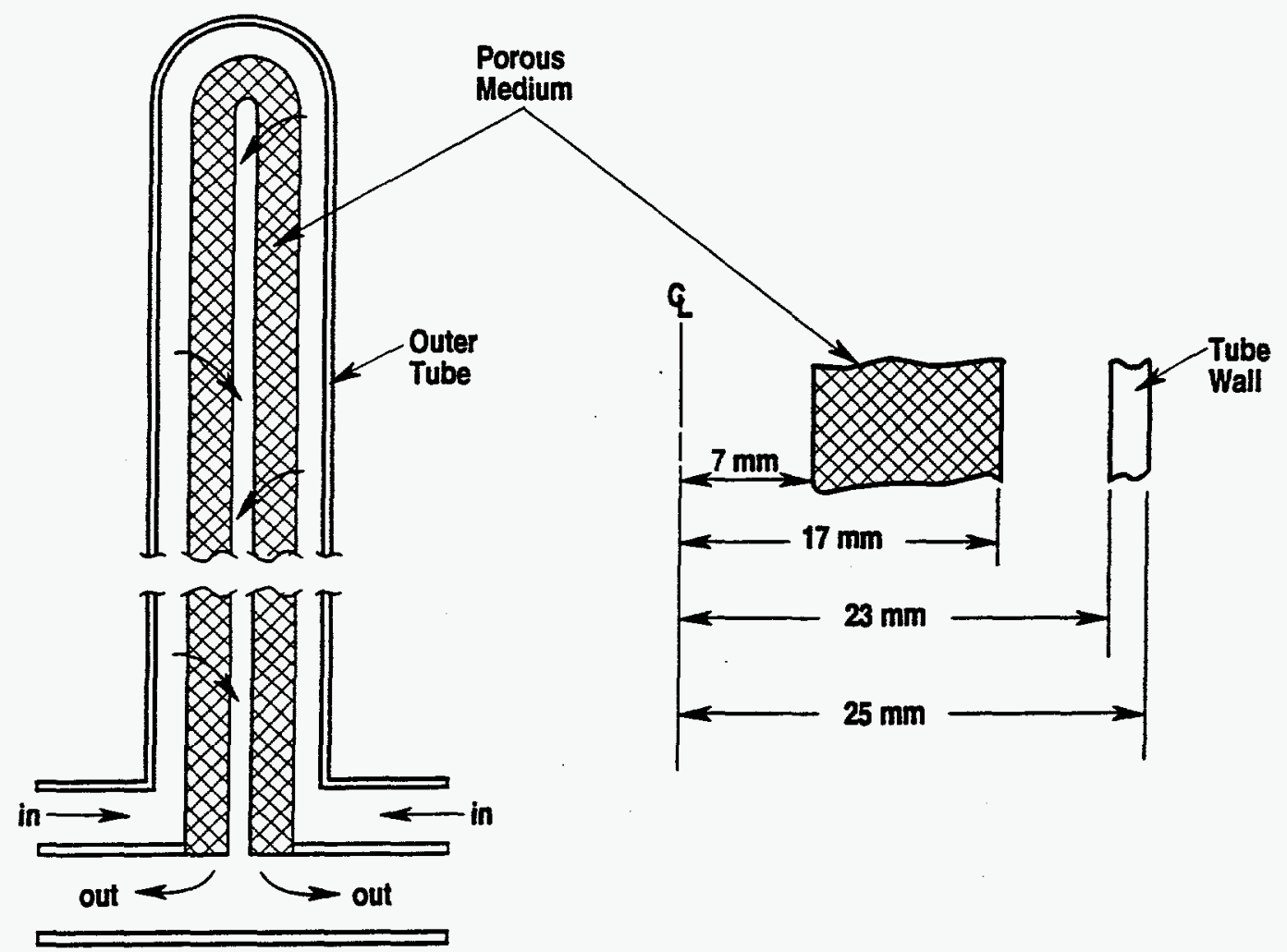

Fig. 12. Particle filter tube schematic. 
The optimum design can be determined by experimenting with different materials, by varying the size of the solid breeder, and by varying the porosity and pore size of the filter. Issues of material compatibility, with and without irradiation effects, will also need to be addressed. For this scoping study, specific porous material, design and particles size have not been selected. Table 1 gives the parameters of the selected helium coolant particle filter tube design:

Table 1

Parameters of Particle Filter Tubes

\begin{tabular}{ll}
\hline Outer tube diameter, $\mathrm{mm}$ & 50 \\
Outer tube wall thickness, $\mathrm{mm}$ & 2 \\
Porous tube outer diameter, $\mathrm{mm}$ & 34 \\
Porous tube inner diameter, $\mathrm{mm}$ & 14 \\
Porous tube height, $\mathrm{m}^{\star}$ & 1 \\
Number of tubes per $2 \mathrm{~m}$ toroidal wide module & 30 \\
Porous foam density, \% & 17 to $22 \%$ \\
Assumed breeder loading fraction in the foam, \% & 40 \\
Calculated volume fraction of breeder in blanket, \% & 1 \\
Breeding material & $\mathrm{Li}_{4} \mathrm{SiO}_{4}$ \\
\hline
\end{tabular}

*For this scoping study, the sub-module height is assumed to be one meter.

\subsection{NEUTRONICS SCOPING CALCULATION}

Based on the Table 1 parameters and using helium as the flowing medium, neutronics calculations were performed to evaluation the TBR potential of the filter design. With a breeder loading fraction of $40 \%$ in the metallic porous medium, the volume fraction of breeder in the blanket is $1 \%$. The material fractions used in the blanket calculation are: $23.5 \% \mathrm{SS}, 70 \% \mathrm{Be}$ and water zone, and $6.5 \%$ for the SS, breeder and $\mathrm{He}$ tube. Retaining the very thin Be-Cu-SS first wall layers has almost no effect on TBR. The Be and water fractions are $60 \%$ and $40 \%$, respectively. Beryllium is assumed to be $90 \%$ dense. Using the 1994 ITER-EDA plant geometry and configuration, at a Li- 6 enrichment of $60 \%$, a 1-D TBR of 1.15 was obtained for the $\mathrm{Li}_{4} \mathrm{SiO}_{4}$. The TBR is only 0.5 when the Li-6 is naturally enriched. This 1-D TBR performance is encouraging as it indicates the 
possibility of reaching the 3-D TBR goal of 0.4 to 0.8 . 1-D and 3-D calculations using a more detailed design geometry and materials composition will be needed.

\subsection{HEAT REMOVAL EVALUATION}

Figure 13 shows the volumetric power generation of different blanket materials normalized to $1 \mathrm{MW} / \mathrm{m}^{2}$ neutron wall loading. At a location very close to the first wall, the maximum volumetric power generation for $100 \%$ dense material is $200 \mathrm{~W} / \mathrm{cm}^{3}$ for $\mathrm{Li}_{4} \mathrm{SiO}_{4}$, and $10 \mathrm{~W} / \mathrm{cm}^{3}$ for stainless steel (SS) 316 . For a $1 \mathrm{~m}$ high purge tube, and with material volumes of $3 \times 10^{-4} \mathrm{~m}^{3}$ and for the breeder $4.65 \times 10^{-4} \mathrm{~m}^{3}$ and for the SS-316, these power densities will generate a power output of $64,650 \mathrm{~W}$ per tube, which corresponds to a surface loading of $0.4 \mathrm{MW} / \mathrm{m}^{2}$ at the purge tube surface. This level of surface loading should not be difficult to remove when the coolant is water. For tubes located further away from the first wall, the power generated per tube will be much lower. Details will have to be further justified by design.

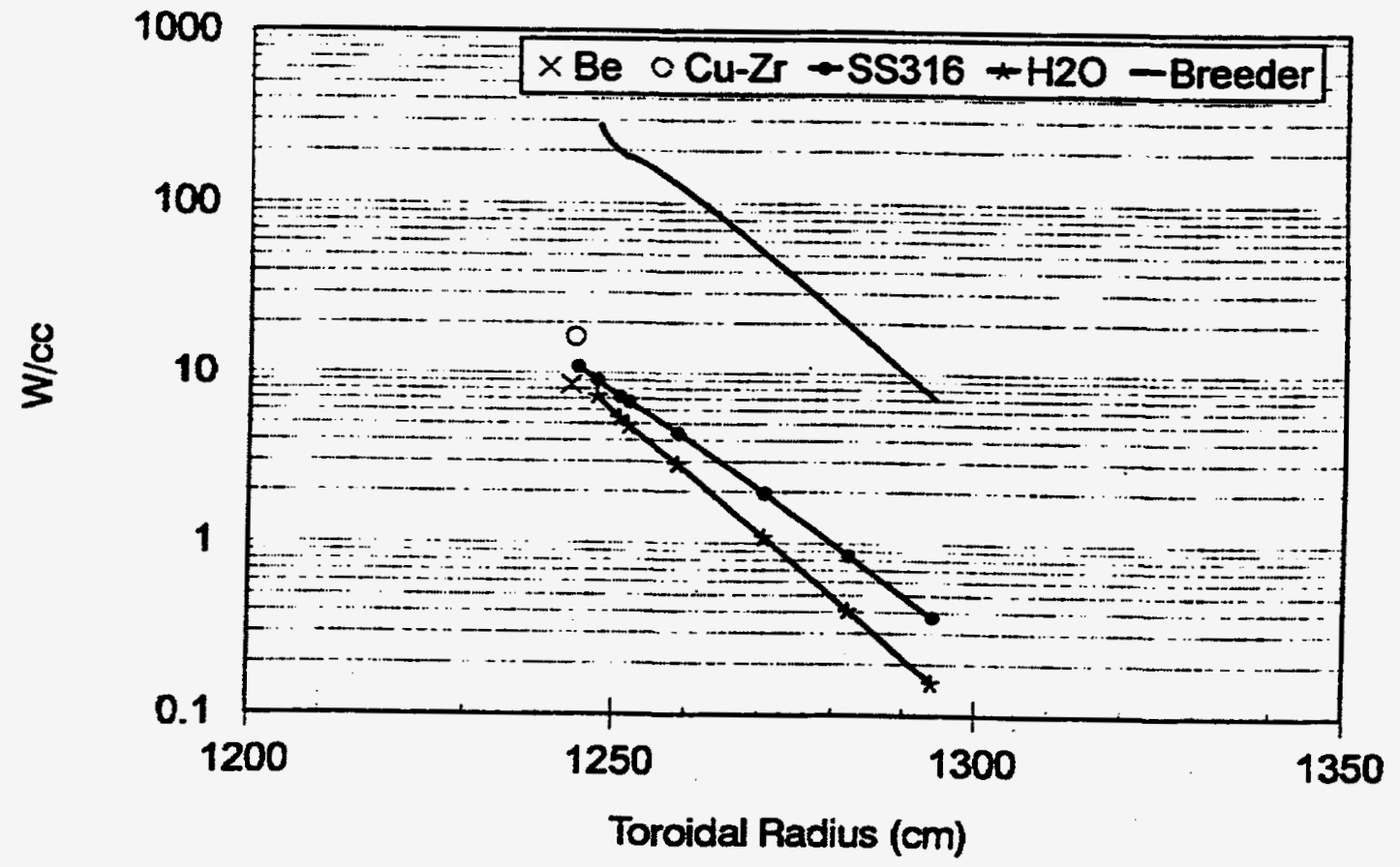

Fig. 13. Nuclear heating rate in $\mathrm{Li}_{4} \mathrm{SiO}_{4}$ breeding blanket (outboard) normalized to $1 \mathrm{MW} / \mathrm{m}^{2}$ at outboard. 


\subsection{CONVERSION CONTROL TIME}

The time it takes to fill the filter to the equilibrium level of solid can be estimated. At a gas pressure of $0.5 \mathrm{MPa}$, the density of helium is about $0.65 \mathrm{~kg} / \mathrm{m}^{3}$ at $100^{\circ} \mathrm{C}$. For a solid-mass-to-gas-mass ratio of 1 (a very dilute gas and solid mixture condition) and a gas velocity of $1 \mathrm{~m} / \mathrm{s}$ at the outlet of the tube, the solid mass flow rate is $9.75 \times 10^{-5} \mathrm{~kg} / \mathrm{s}$. Therefore, accumulation of $0.684 \mathrm{~kg}$ of solid breeder per tube takes a very reasonable $7015 \mathrm{~s} \mathrm{(} 2$ hours). Since this is a relatively conservative estimate, it shows the feasibility and flexibility of the concept. The amount and rate of breeder deposition can be controlled by the amount of material injected and the rate of helium flow. This is a potential mechanism for control of blanket power and tritium generation.

\subsection{REFERENCE SHIELD DESIGN IMPACT}

Compared to the proposed convertible blanket options, the particle filter concept seems to have the minimum impact on the design and maintenance approach of the reference SS water-cooled shield ITER-EDA design of 1994. Four basic modifications will need to be made:

1. SS shield filler material will have to be replaced by Be neutron multiplier . Although this will impact the lifetime of the shield blanket, it seems to be a generic issue for a convertible blanket.

2. Design modification will be needed for the insertion of purge tubes from the bottom of each sub-module.

3. A tritium purge flow and breeder delivery system will have to be designed. The purge flow plenum, which will be similar to the water coolant plenum at the back of the blanket, will need to be added.

4. The water cooling system will have to be re-optimized to account for the removal of power generated from the purge tubes during EPP. 


\subsection{ADVANTAGES}

Compared to the proposed convertible blanket options, the particle filter design has the following advantages:

1. The procedure for conversion of shield to breeding blanket seems to be relatively credible and straight forward. Some solid will be attached to the manifolds and channel walls due to electrostatic effect. The amount should be minimized for the accountability of bred tritium, but it is not a feasibility issue.

2. The conversion period for this design can be adjusted by fluid flow rate and solid loading fraction. This flexibility allows a relatively soft conversion from the shielding to breeder blanket, and allows the breeding of tritium even during the BPP.

3. The basic concern of particle erosion for the gas particle mixture design should not be serious for the particle filter design, since the frequency of particle fill and replacement should be quite low.

4. The particle filter approach allows the replacement of breeder material for reasons of breeder performance, material compatibility or material burn-up, and also allows the control of blanket power and tritium generation.

5. This design seems to have minimum impact on the heat transfer of the reference design approach. Due to the small amount of breeder material used, the increased power can possibly be handled by water coolant flow rate adjustment without the risk of violating material temperature limits.

6. The purge flow fluid, either water or helium, can perform three functions: (a) the purge flow fluid for tritium removal, (b) the breeder delivery fluid and (c) the fluid to equalize the filter tube temperature. The purge flow fluid can be used to remove part of the generated power, but its main heat transfer function is to re-distribute the breeder power to the surfaces of the tube.

7. This design configuration will not disturb the sub-module maintenance approach of the present reference shield design. 


\subsection{DISADVANTAGES}

Disadvantages of the particle filter tube design are:

1. Large amounts of Be will be needed. A design incorporating Be-swelling tolerances might be necessary for operation to the end of EPP. However, this seems to be a generic concern of convertible blanket designs.

2. When water is used as the tritium purge and particle delivery fluid, although the shielding effectiveness of the shield can be preserved, tritium will need to be removed from water. In addition, a water-compatible solid breeder will be necessary.

3. When helium is used as the tritium purge and particle delivery fluid, the shield will need to be thicker by a few percent in order to counter the void space created by the use of helium and maintain the same shielding effectiveness.

4. With the addition of the filter tube and the corresponding fluid routing system, the blanket design will be more complicated. However, it appears that fabrication can be based on existing technology. 


\section{CONCLUSIONS AND RECOMMENDATIONS}

Some of the proposed convertible blankets have feasibility problems in particle transfer and material distribution control. Others can have problems in heat transfer and tritium breeding performance. The particle filter concept is introduced, which seems to be able to satisfy all the design requirements except the generic issue of Be blanket lifetime.

Since this is a minimum-effort scoping evaluation, a more detailed design and analysis will be needed before pursuing the particle filter concept further. If the concept continues to look promising, a development plan should be formulated. 


\section{REFERENCES}

[1] Sviatoslavsky, I.N., "Summary and Assessment of Convertible Solid Breeder Blankets," University of Wisconsin, Madison, issued September, 1994.

[2] Pamphlet from SELEE corporation, "Ceramic Foam Products For Industry," 700 Shepherd Street, Hendersonville, NC 28792. 